\title{
Identification and Characterization of Menadione and Benzethonium Chloride as Potential Treatments of Pierce's Disease of Grapevines
}

\author{
S. Zhang, M. Jain, L. A. Fleites, P. A. Rayside, and D. W. Gabriel ${ }^{\dagger}$
}

Department of Plant Pathology, University of Florida, Gainesville 32611.

Current address of S. Zhang: New Mexico Consortium Biolab, Los Alamos, NM 87544.

Current address of L. A. Fleites: Boyce Thompson Institute, Ithaca, NY 14853.

Accepted for publication 29 October 2018.

\begin{abstract}
Xylella fastidiosa infects a wide range of plant hosts and causes Pierce's disease (PD) of grapevines. The type 1 multidrug resistance (MDR) efflux system is essential for pathogenicity and survival of bacterial pathogens in planta. X. fastidiosa, with a single MDR system, is significantly more vulnerable to inhibition by small-molecule treatments than most bacterial pathogens that typically carry redundant MDR systems. A high-throughput cell viability assay using a green fluorescent protein-marked strain of $X$. fastidiosa Temecula 1 was developed to screen two Prestwick combinatorial small-molecule libraries of drugs and phytochemicals (1,600 chemicals in total) approved by the Food and Drug Administration and European Medicines Agency for cell growth inhibition. The screens revealed 215

chemicals that inhibited bacterial growth by $>50 \%$ at $50 \mu \mathrm{M}$ concentrations. Seven chemicals proved to lyse X. fastidiosa cells at $25 \mu \mathrm{M}$, including four phytochemicals. Menadione (2-methyl-1,4-naphthoquinone, vitamin K) from the phytochemical library and benzethonium chloride (a topical disinfectant) from the chemical library both showed significant bactericidal activity against $X$. fastidiosa. Both menadione and benzethonium chloride foliar spray (15 and $5 \mathrm{mM}$, respectively) and soil drench (5 and $25 \mathrm{mM}$, respectively) treatments were equally effective in reducing PD symptoms by 54 to $59 \%$ and revealed that the effects of both chemical treatments became systemic. However, menadione was phytotoxic when applied as a foliar spray at effective concentrations, causing significant loss of photosynthetic capacity.
\end{abstract}

Xylella fastidiosa is a fastidious, insect-vectored, Gram-negative, xylem-limited bacterium with a broad host range across 300 different plant species in 63 different families (Rapicavoli et al. 2018a). X. fastidiosa causes several economically important diseases such as Pierce's disease (PD) of grapevines (Vitis vinifera), citrus variegated chlorosis, alfalfa dwarf, phony peach disease, leaf scorch of plum and almond, periwinkle wilt, and the recently emerging olive quick decline syndrome. $X$. fastidiosa strains are also associated with diseases in mulberry, pear, elm, sycamore, oak, maple, pecan, and coffee (Purcell and Hopkins 1996; Rapicavoli et al. 2018a). In grapevines, $X$. fastidiosa cells multiply and spread readily from the site of infection, leading to systemic colonization of the xylem in susceptible plants. Xylem occlusion results in marginally progressing leaf necrosis, desiccation of berries, and abnormal abscission of petioles, eventually resulting in death of the infected vines. Characteristic scorching of the leaves, although associated with water stress, typically occurs in bands, suggesting either toxin or pathogenicity effector activity (Goodwin et al. 1988; Stevenson et al. 2005; Thorne et al. 2006; Zhang et al. 2015). The economic consequences of PD to the California grape industry alone is estimated at $\$ 100$ million per year (Alston et al. 2015).

By contrast with most other phytopathogenic bacteria, $X$. fastidiosa lacks a type III secretion system as well as type III effectors that condition pathogenicity, virulence, or suppression of plant defenses. Instead, genes encoding type I, II, and V secretion systems and their effectors have been confirmed to determine

†Corresponding author: D. W. Gabriel; E-mail: dgabr@ufl.edu

Funding: This research was supported by California Department of Food and Agriculture agreement number 15-0215-SA.

S. Zhang and M. Jain contributed equally to the work.

*The $\boldsymbol{e}$-Xtra logo stands for "electronic extra" and indicates that three supplementary tables are published online.

(c) 2019 The American Phytopathological Society pathogenicity in the genome of X. fastidiosa (Chatterjee et al. 2008; Guilhabert and Kirkpatrick 2005; Rapicavoli et al. 2018a; Zhang et al. 2015). The type I secretion system is involved in processes such as drug resistance via multidrug resistance (MDR) efflux and secretion of proteases, hydrolases, and toxins (Delepelaire 2004; Zhang et al. 2015). In Gram-negative bacteria, the type I translocator channel is composed of two inner membrane protein components attached to a highly conserved protein, TolC, that traverses both the periplasm and outer membrane (Holland et al. 2005). Multidrug efflux has been functionally implicated in tolerating plant defenses in Erwinia chrysanthemi (Barabote et al. 2003), E. amylovora (Burse et al. 2004), Agrobacterium tumefaciens (Peng and Nester 2001), Rhizobium etli (Gonzales-Pasayo and Martinez-Romero 2000), and Bradyrhizobium japonicum (Krummenacher and Narberhaus 2000).

The MDR efflux system of $X$. fastidiosa is essential for both pathogenicity and survival of the PD pathogen in grapevines (Reddy et al. 2007). MDR efflux in $X$. fastidiosa is functionally dependent on tolC, encoding the outer membrane and periplasmic tunnel components, and $a \mathrm{crF}$, encoding the inner membrane component of the type I system. $X$. fastidiosa strains have only single homologs of both tolC and $a c r F$, in contrast to most plant pathogens, which have multiple and redundant tolC genes and MDR efflux system components. Knockout mutations of tolC rendered $X$. fastidiosa nonpathogenic and mutant strains could not be recovered from inoculated plants (Reddy et al. 2007). Knockout mutations of $a c r F$ reduced pathogenicity of the mutants (D. W. Gabriel lab, unpublished data).

During the course of the above investigations, it was evident that even wild-type $X$. fastidiosa, with its lone MDR efflux system, was much more sensitive to plant-derived antimicrobial chemicals than most other plant pathogens typically carrying multiple efflux systems (Reddy et al. 2007; Tegos et al. 2002). MDR efflux mutants have been useful in highly sensitive and quantitative screens for evaluating antimicrobial chemicals in diverse pathological systems with redundant type I systems (Tegos et al. 2011). The objective of 
this project was to exploit the increased vulnerability of $X$. fastidiosa to chemicals requiring MDR efflux to develop a high-throughput, sensitive, and quantitative live cell screen applicable to small-molecule combinatorial libraries for lead discovery and evaluation of chemicals with potential for use to control PD.

\section{MATERIALS AND METHODS}

Small-molecule combinatorial libraries. The Prestwick Chemical Library (1,120 small molecules, 95\% drugs approved by Food and Drug Administration and European Medicines Agency) and the Prestwick Phytochemical Library (320 natural plantderived chemicals) were purchased from Prestwick Chemical (Illkirch, Bas-Rhin, France) in dimethyl sulfoxide (DMSO) in a 96-well plate format (each chemical at $10 \mathrm{mM}$ concentration).

Florescent (green fluorescent protein)-marked $X$. fastidiosa Temecula 1/pSZ90. $X$. fastidiosa $\mathrm{PD}$ strain Temecula 1 was grown at $28^{\circ} \mathrm{C}$ in PD 3 medium, consisting of tryptone at $4 \mathrm{~g} \mathrm{liter}^{-1}$; soytone peptone at $2 \mathrm{~g}$ liter $^{-1}$; trisodium citrate, disodium succinate, $\mathrm{MgSO}_{4} \cdot 7 \mathrm{H}_{2} \mathrm{O}$, and $\mathrm{KH}_{2} \mathrm{PO}_{4}$ at $1 \mathrm{~g}$ liter ${ }^{-1}$ each; $\mathrm{K}_{2} \mathrm{HPO}_{4}$ at $1.5 \mathrm{~g}$ liter $^{-1}$; and $0.1 \%$ (wt/vol) hemin chloride at $10 \mathrm{ml} \mathrm{liter}^{-1}$. The $\mathrm{pH}$ was adjusted to 7.0 prior to adding soluble potato starch at $2 \mathrm{~g} \mathrm{liter}^{-1}$ and agar at $15 \mathrm{~g}$ liter $^{-1}$. The $P_{t r p}:: g f p$ cassette was polymerase chain reaction (PCR) amplified from pUFZ75 (Zhang et al. 2009) using primers 5' GGG GTA CCG CTC TAA GAA GCT TGG CAA ATA TAC $3^{\prime}$ and 5' GCG TCG ACC TAT TTG TAT AGT TCATCC ATG CCA TG 3', and cloned into pCR2.1-TOPO (Invitrogen, Carlsbad, CA). Following sequence confirmation, the $P_{t r p}:: g f p$ cassette was subcloned in the wide-host-range shuttle vector pBBR1MCS-5 (Bordatella replicon) (Kovach et al. 1995). The resulting plasmid pSZ90 was introduced into PD strain Temecula 1 as described by Zhang et al. (2015).

$X$. fastidiosa culture conditions and high-throughput assay conditions. Starter cultures of green fluorescent protein (GFP)-marked $X$. fastidiosa (Temecula $1 / \mathrm{pSZ} 90$ ) were grown in PD3 medium plus gentamycin at $3 \mu \mathrm{g} \mathrm{ml} \mathrm{m}^{-1}$ for 3 days and subsequently diluted. In initial experiments, 100,150 , and $300 \mu l$ of PD3 medium with or without Silwet L-77 at 200 ppm were inoculated from starter cultures into black polystyrene 96-well microtiter plates preloaded with medium with different inoculum densities of $X$. fastidiosa Temecula $1 / \mathrm{pSZ} 90$ and incubated with orbital shaking at $28^{\circ} \mathrm{C}$ at a speed of 120 revolutions $/ \mathrm{min}$. Silwet L77 was added to enable detection of antimicrobial chemicals that might specifically affect the $X$. fastidiosa MDR efflux pump (Reddy et al. 2007). Optical density at $600 \mathrm{~nm}\left(\mathrm{OD}_{600 \mathrm{~nm}}\right)$ and GFP fluorescence $\left(\lambda_{\text {ex }}=485 / 20 \mathrm{~nm}\right.$ and $\lambda_{\text {em }}=528 / 20 \mathrm{~nm}$ ) data were recorded for 6 days using a BioTek Synergy HTX multimode reader (BioTek, Winooski, VT).

For the Prestwick library screens, different chemicals were initially screened at 50- $\mu \mathrm{M}$ concentrations in the preloaded medium and were seeded with starter cultures diluted to $\mathrm{OD}_{600 \mathrm{~nm}}=0.05$ culture $\left(150 \mu \mathrm{l} \mathrm{well}^{-1}\right)$. The outermost columns (provided as blanks in the Prestwick library format) were inoculated in the presence of either ampicillin at $1 \mu \mathrm{g} \mu \mathrm{l}^{-1}+1 \%$ DMSO (positive control, $100 \%$ lethality) or $1 \%$ DMSO (negative control, no lethality) treatments. To test whether the small-molecule-induced growth inhibition was due to perturbed outer-membrane barrier functions, Silwet L-77 at 200 ppm was added in PD3 medium in a duplicate plate with a similar layout. Plates were briefly centrifuged and incubated at $28^{\circ} \mathrm{C}$. Bacterial growth was measured at $48 \mathrm{~h}$ after inoculation, both as (correlated) increase in OD $\left(\mathrm{OD}_{600 \mathrm{~nm}}\right)$ and as GFP fluorescence $\left(\lambda_{\mathrm{ex}}=485 / 20 \mathrm{~nm}\right.$ and $\left.\lambda_{\mathrm{em}}=528 / 20 \mathrm{~nm}\right)$ (Steff et al. 2001). The experiments were repeated three times, initiated with different starter cultures and on different days.

The Z' factor (Zhang et al. 1999) was calculated according to the following formula: $Z^{\prime}=1-\left[\left(3 \sigma \mathrm{CK}^{-}+3 \sigma \mathrm{CK}^{+}\right) /\left(\mu \mathrm{CK}^{-}-\mu \mathrm{CK}^{+}\right)\right]$, where $\sigma$ are standard deviations and $\mu$ are the average fluorescence read changes of the negative and positive controls over a period of
$48 \mathrm{~h}$. The average fluorescence read changes of negative control $\left(\mu \mathrm{CK}^{-}\right)$and the fluorescence read change of each chemical (f) were used to calculate the percent inhibitory activity according to the following equation: percent inhibition $=\left[1-\mathrm{f} / \mu \mathrm{CK}^{-}\right] \times 100$.

Phytotoxicity evaluation and photosynthesis measurements. Three leaf disc explants (10 $\mathrm{mm}$ in diameter) from young fully expanded grapevine leaves ( $V$. vinifera 'Carignane') were floated on Murashige and Skoog (MS) basal medium (Murashige and Skoog 1962) amended with different concentrations of menadione and benzethonium chloride. Three days after treatment, leaf pigments were extracted in $80 \%$ ( $\mathrm{vol} / \mathrm{vol})$ acetone and total chlorophyll content was quantified as described by Arnon (1949). Photosynthetic $\mathrm{CO}_{2}$ assimilation rates were measured according to Jain et al. (2012) in untreated healthy control, X. fastidiosa-inoculated, and chemical-treated grapevines with a portable photosynthesis gas exchange measurement system (LI-6400; LI-COR, Lincoln, NE) using the following parameters: $28^{\circ} \mathrm{C}$ leaf temperature, $21 \% \mathrm{O}_{2}$, light at $1,200 \mu \mathrm{mol} \mathrm{m} \mathrm{m}^{-2} \mathrm{~s}^{-1}$, and $75 \%$ relative humidity at $350 \mu$ bar $\mathrm{CO}_{2}$ concentration. The data were collected for four fully expanded young leaves per plant.

X. fastidiosa pathogenicity assays. Grapevines, approximately $90 \mathrm{~cm}$ tall in 3.8 liter pots, were inoculated with $X$. fastidiosa using the needle puncture method, as previously described (Zhang et al. 2015). Five-day-old cultures of $X$. fastidiosa Temecula 1 were grown in PD medium and resuspended to a final $\mathrm{OD}_{600 \mathrm{~nm}}=0.25$ in SCP buffer containing trisodium citrate, disodium succinate, $\mathrm{MgSO}_{4} \cdot 7 \mathrm{H}_{2} \mathrm{O}$, and $\mathrm{KH}_{4} \mathrm{PO}_{4}$ at $1 \mathrm{~g}$ liter ${ }^{-1}$ each and $\mathrm{K}_{2} \mathrm{HPO}_{4}$ at $1.5 \mathrm{~g} \mathrm{liter}^{-1}, \mathrm{pH}$ 7.0. A 10- $\mu$ l droplet of bacterial suspension was applied in the middle of the internode and the bark tissue was punctured through the adhering droplet using a sterile tuberculin needle. Inoculations were made on alternating sides of four to five internodes, starting with the second internode from the base. Plant irrigation was withheld for at least $36 \mathrm{~h}$ prior to inoculation, facilitating the rapid intake of droplets of bacterial suspension into the xylem stream. Chemical controls, either soil drenches or spray treatments, were applied immediately following inoculation. The same chemical treatments were repeated twice later, at the end of 30 - and 60-day periods. Disease severity was quantified by counting the total number of diseased leaves (symptomatic leaves, bare petioles, and bare nodes) and the data presented as percentage of total number of nodes (bare or with symptomatic or asymptomatic leaves attached).

\section{RESULTS}

Optimization of $X$. fastidiosa Temecula $1 / p S Z 90$ culture conditions for a high-throughput bioassay to screen Prestwick small-molecule combinatorial libraries. To determine Temecula $1 /$ pSZ90 growth characteristics in flat-bottom 96-well plates, 100, 150 , and $300 \mu 1$ of PD3 medium with or without Silwet L-77 at 200 ppm was inoculated with different initial inoculum densities from starter cultures and incubated with orbital shaking at $28^{\circ} \mathrm{C}$. The $150-$ $\mu \mathrm{l}$ volume of seed culture per well was found to be optimal for consistent growth. Under these culture conditions, GFP fluorescence increased with OD and both correlated well with cell viability. All treatments adversely affecting bacterial viability (OD) also resulted in loss of GFP fluorescence due to protein degradation. Growth of the $\Delta$ tolC mutant strain was strongly suppressed by Silwet L-77 at 200 ppm, with a concomitant suppression of GFP accumulation. Similarly, antibiotic treatments that decreased cell viability also reduced GFP fluorescence (data not shown). Maximum growth was achieved within $48 \mathrm{~h}$ (Fig. 1).

Screening of Prestwick chemical and phytochemical combinatorial libraries for identification of small molecules affecting growth of $X$. fastidiosa. For the primary screen, plates were seeded with $X$. fastidiosa Temecula 1/pSZ90 cells with or without Silwet L-77 at 200 ppm and with each tested chemical loaded at a concentration of $50 \mu \mathrm{M}$, in two independent 
experiments. The statistical parameter $\left(Z^{\prime}\right)$ was used to evaluate the quality of the assays exactly as described (Zhang et al. 1999). The overall $Z^{\prime}$ scores for the Prestwick Chemical and Phytochemical libraries were 0.78 and 0.76 , respectively; within the statistically “excellent" reproducibility range ( $\left.Z^{\prime}>0.75\right)$ (Zhang et al. 1999).

Significant growth inhibition $(>50 \%)$ of $X$. fastidiosa Temecula 1/pSZ90 was observed with 193 chemicals (Fig. 2; Supplementary Table S1). Among them, 91 chemicals exhibited growth inhibition between 90 to $100 \%$ as compared with controls and 30 chemicals exhibited $100 \%$ growth inhibition. Some chemicals (for example tetracycline, chlortetracycline, erythromycin, puromycin, rifampicin, and minocycline) have either antibiotic or major pharmaceutical uses. These were eliminated from further consideration because of anticipated regulatory concerns. Six chemicals (disulfiram, pinaverium bromide, methyl benzethonium chloride, benzethonium chloride, cephalothin sodium salt, and nitazoxanide) exhibited significant growth inhibition that appeared to be possibly enhanced by Silwet L-77 in the primary screen. However, further evaluation in dose-dependent secondary screens at concentrations of 25,50 , and $100 \mu \mathrm{M}$ revealed no such enhancement (Supplementary Table S3), thus precluding any conclusions of significant effects on membrane barrier functions or TolC from any of the chemicals screened in these tests. Benzethonium chloride, a

Temecula $1+$ Silwet L-77 $\Delta$ tolC - Silwet L-77

Temecula 1 - Silwet L-77 $\Delta$ tolC + Silwet L-77
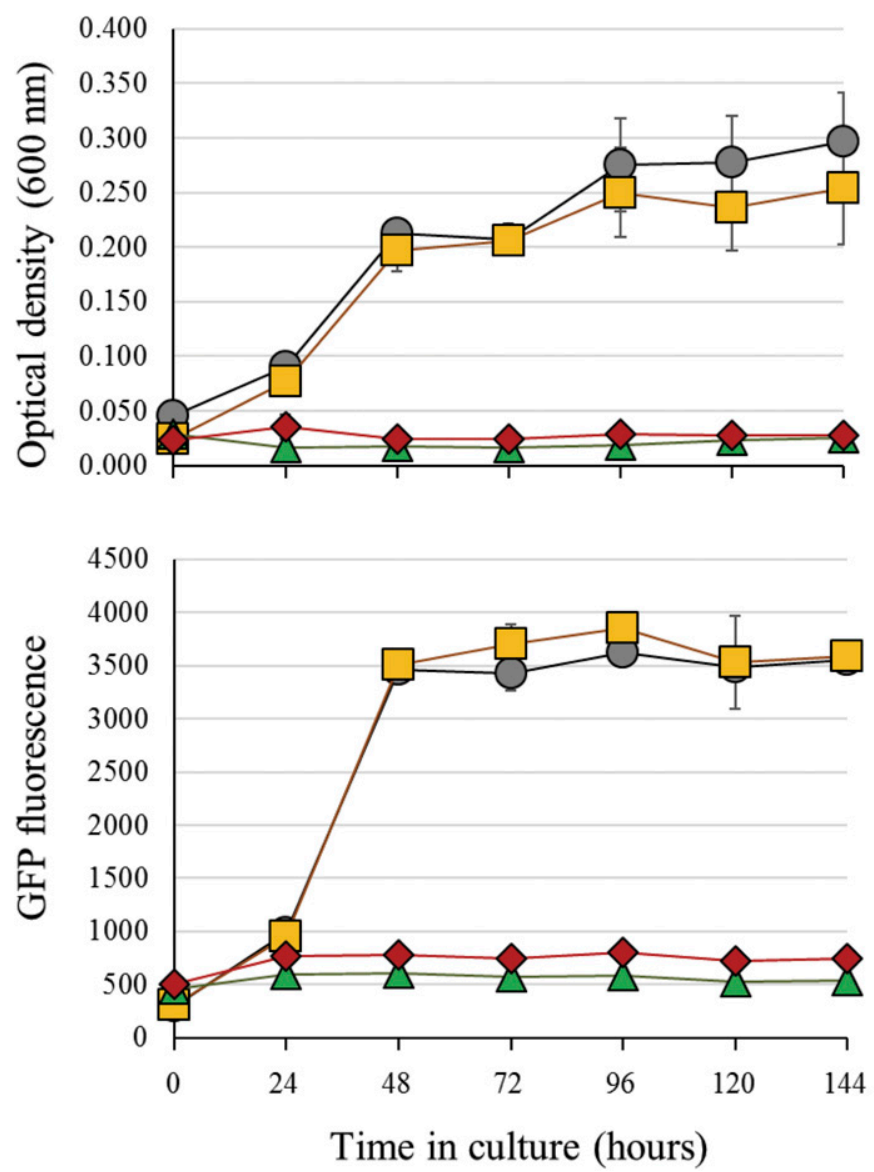

Fig. 1. Optimal growth of Xylella fastidiosa Temecula 1/pSZ90 without contamination in the 96-well plate format was reproducibly achieved using the $150-\mu \mathrm{l}$ culture volume per well, with the initial inoculation density of an optical density at $600 \mathrm{~nm}=0.05$. Under these culture conditions, green fluorescent protein (GFP) fluorescence and optical density were correlated with cell viability because any treatment adversely affecting cell viability also resulted in loss of GFP fluorescence due to protein degradation. Maximum growth was achieved within $48 \mathrm{~h}$. commonly used topical disinfectant, provided $100 \%$ growth inhibition in three independently conducted secondary screens at all concentrations tested (25 to $100 \mu \mathrm{M})$ and was selected for evaluation against PD.

Similarly, the phytochemical library screen revealed significant growth inhibition $(>50 \%)$ of $X$. fastidiosa Temecula $1 / \mathrm{pSZ} 90$ by 22 phytochemicals (Fig. 2; Supplementary Table S2). Six phytochemicals [menadione, 9-methoxyellipticine, olivacine, gossypol, 4,4' (2,3 dimethyltetramethylene)dipyrocatechol, and roseoflavin] exhibited $>90 \%$ inhibition of bacterial growth. None of the 320 phytochemicals displayed evidence of enhanced inhibition in the presence of Silwet L-77 at 200 ppm. Menadione provided $100 \%$ growth inhibition in secondary screens at concentrations of 25, 50, and $100 \mu \mathrm{M}$, and was also selected for evaluation against PD.

Phytotoxicity evaluation of menadione and benzethonium chloride. Prior to conducting greenhouse experiments for PD control, phytotoxicity of menadione and benzethonium chloride was quantitatively measured by chlorophyll loss in leaf disc senescence assays (Fig. 3) to help determine appropriate or

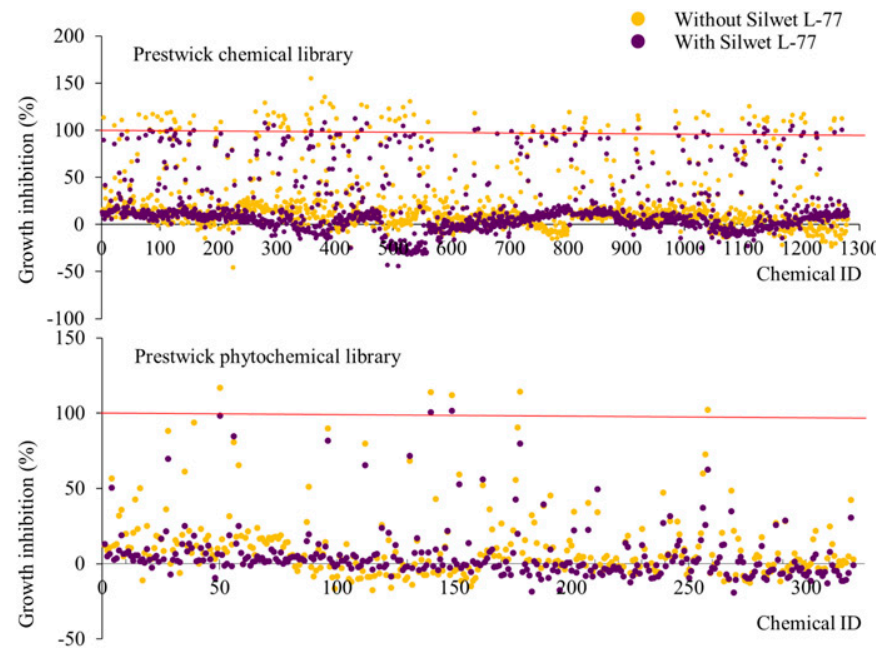

Fig. 2. Growth inhibition (\%) of green fluorescent protein-marked Xylella fastidiosa Temecula 1/pSZ90 after $48 \mathrm{~h}$ in the presence and absence of surfactant Silwet L-77 (200 ppm) across two Prestwick combinatorial smallmolecule libraries (drugs and phytochemicals approved by the Food and Drug Administration and European Medicines Agency; 1,600 chemicals in total).

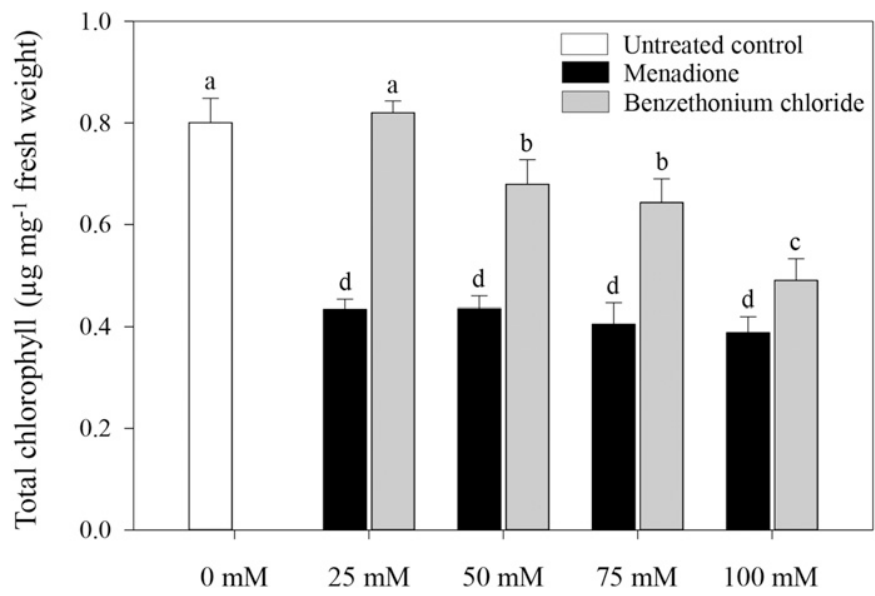

Fig. 3. Effect of menadione and benzethonium chloride treatments on total chlorophyll content in Vitis vinifera 'Carignane' grapevine leaf discs. Three leaf discs (10 $\mathrm{mm}$ in diameter) were floated in Murashige and Skoog medium at indicated concentrations for $18 \mathrm{~h}$. Total chlorophyll was extracted overnight in $80 \%$ acetone and quantified. Means $( \pm$ standard deviation) marked with different letters are significantly different based on Tukey-Kramer's mean separation $(P \leq 0.05)$. 
maximum treatment concentrations. Leaf disc explants from young, fully expanded $V$. vinifera grapevine leaves were floated on MS medium containing 25 to $100 \mathrm{mM}$ menadione and benzethonium chloride, as indicated. Benzethonium chloride is a surfactant that caused leakage of chlorophyll pigments from the cut sites. However, benzethonium chloride treatment was not significantly detrimental to cellular membranes and chlorophyll integrity at lower concentrations. Grapevine leaves were found to be very sensitive to menadione treatment and resulted in nearly 40 to $45 \%$ loss in total chlorophyll content within $18 \mathrm{~h}$ at all concentrations tested as compared with water-treated control leaf discs. This response was not dose dependent. By contrast, benzethonium chloride-treated leaf discs exhibited a dose-dependent response in the chlorophyll degradation assay and, although no phytotoxicity was observed at $25 \mathrm{mM}$, an increasing loss in chlorophyll content was observed at 50-, 75-, and 100-mM treatments (to approximately $33 \%$ loss at $100 \mathrm{mM}$ ).

Menadione and benzethonium chloride were used at 15- and 25-mM concentrations, respectively, for foliar sprays and at 5- and 25-mM concentrations, respectively, for soil drenches in greenhouse experiments (Fig. 4). Sporadic patches of purple pigmentation and necrosis were evident following foliar sprays of menadione, particularly wherever the spray droplets
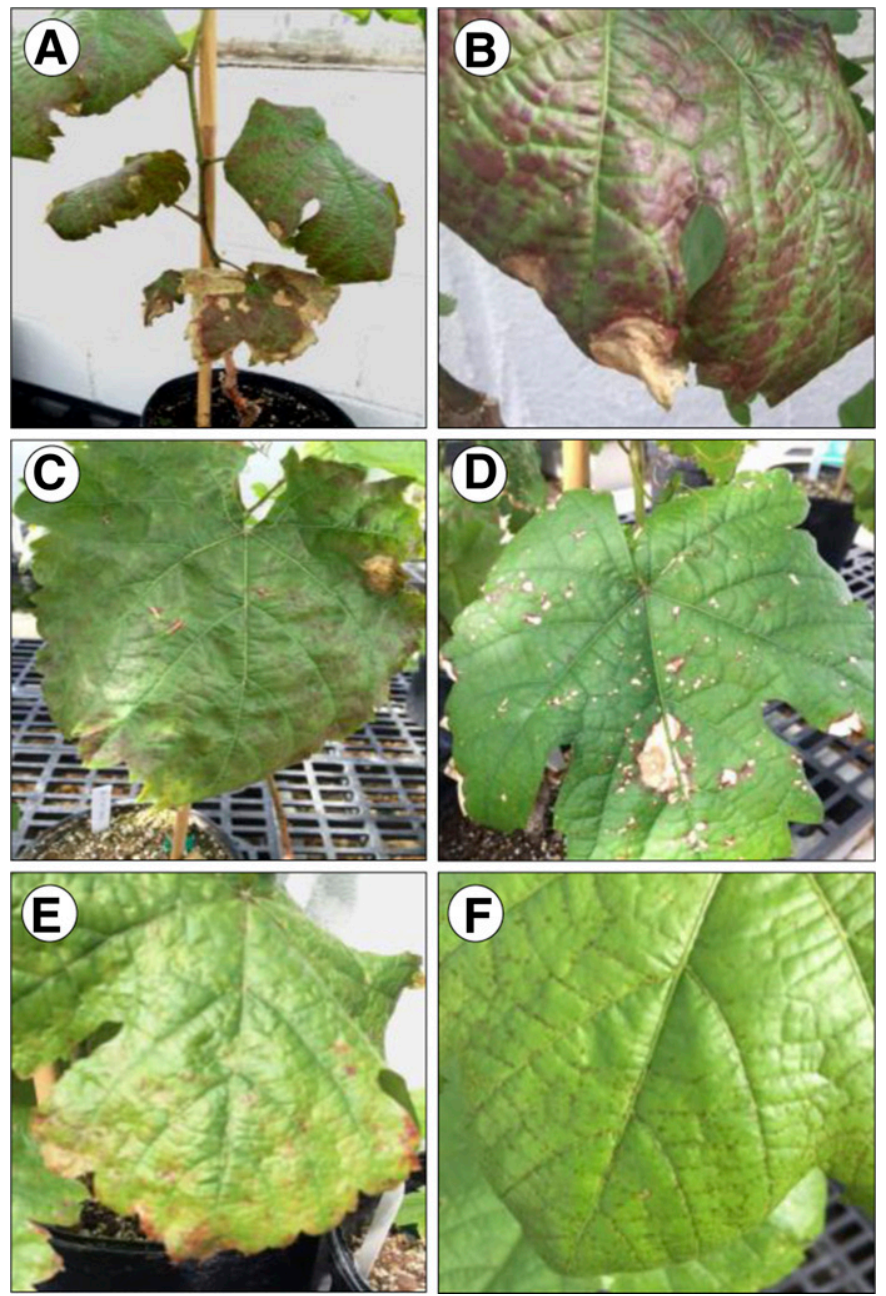

Fig. 4. Effect of menadione and benzethonium chloride treatments on Pierce's disease symptoms and on Vitis vinifera 'Carignane' grapevine leaves. $\mathbf{A}$ and $\mathbf{B}$, Untreated controls inoculated with Xylella fastidiosa Temecula 1; $\mathbf{C}$ and $\mathbf{D}$, menadione treatments, applied as a 5-mM soil drench (C) and 15-mM foliar spray (D); and $\mathbf{E}$ and $\mathbf{F}$, benzethonium chloride treatments, applied as a $25-\mathrm{mM}$ soil drench (E) and 25-mM foliar spray (F). Photos were taken 3 weeks postinoculation, showing lower leaves above the first inoculated internode. accumulated on the leaf blade surface (Fig. 4D). Visible phytotoxicity was not evident with foliar sprays of benzethonium chloride (Fig. 4F) or with soil drench treatments using either chemical (Fig. 4C and E), indicating soil drenches to be the preferred application method.

Menadione and benzethonium chloride treatments delay the progression of PD symptoms in $V$. vinifera grapevines. $V$. vinifera grapevines treated with $5 \mathrm{mM}$ menadione or $25 \mathrm{mM}$ benzethonium chloride for foliar sprays, and $15 \mathrm{mM}$ menadione or $25 \mathrm{mM}$ benzethonium chloride for soil drenches, all showed significantly reduced as well as delayed progression of PD symptoms when assessed over a 3-month period (Fig. 5). Following stem inoculations of untreated grapevines with $X$. fastidiosa Temecula 1 , approximately $40 \%$ of the leaves showed PD symptoms at the end of a 1-month period, progressing to nearly $100 \%$ of the leaves either defoliating or symptomatic at the end of 3 months. By contrast, both menadione as well as benzethonium chloride limited the spread of PD symptoms to approximately $50 \%$ of the grapevine nodes at the end of 3 months, with limited defoliation and few bare petioles or nodes.

Effect of menadione and benzethonium chloride treatments on photosynthetic efficiency of $V$. vinifera grapevine leaves. Gas exchange measurements were used to determine photosynthetic $\mathrm{CO}_{2}$ assimilation rates of $V$. vinifera grapevines showing PD symptoms as well as those treated with menadione and benzethonium chloride (Fig. 6). The photosynthetic efficiency of untreated grapevine leaves showing PD symptoms was severely compromised as compared with $X$. fastidiosa-inoculated and treated leaves, and as well as healthy and untreated control plants. Foliar spray treatment of inoculated plants with $15 \mathrm{mM}$ menadione resulted in an observably phytotoxic response and a significant $35.5 \%$ loss in photosynthetic efficiency. Benzethonium chloride $(25 \mathrm{mM}$, soil drench) caused a $21.4 \%$ loss of photosynthetic rate. Grapevines inoculated with $X$. fastidiosa Temecula 1 and treated with $5 \mathrm{mM}$ menadione (soil drench) and $25 \mathrm{mM}$ benzethonium chloride (foliar spray) maintained adequate $\mathrm{CO}_{2}$ assimilation rates, with only 15.2 and $12.3 \%$ reductions,

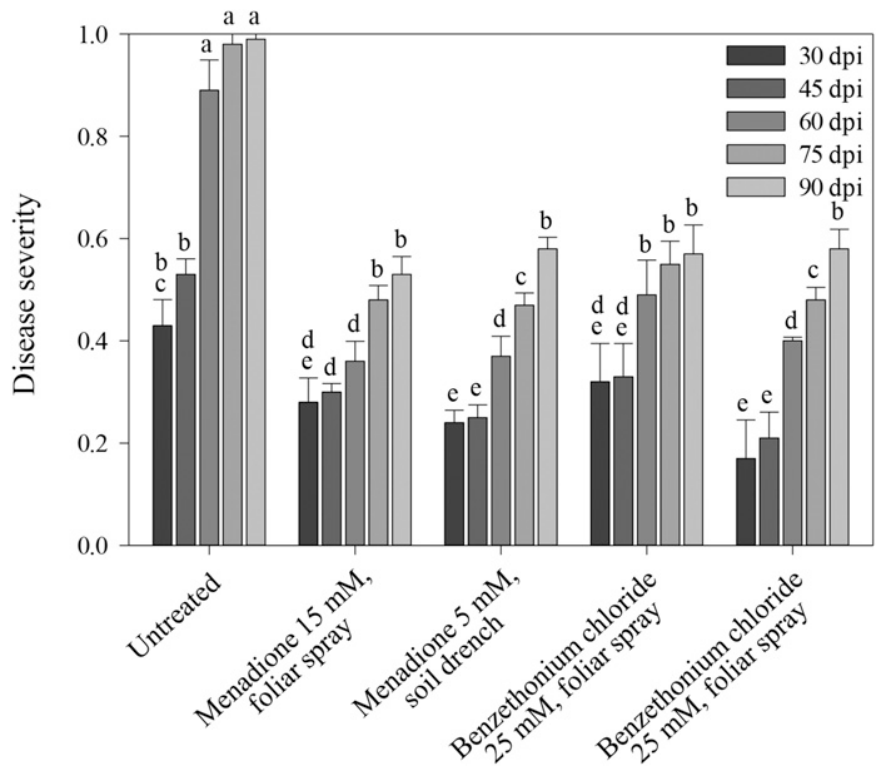

Fig. 5. Effect of menadione and benzethonium chloride treatments applied as soil drench or foliar spray on progression of Pierce's disease symptoms on Vitis vinifera 'Carignane' grapevines over a 3-month period. Chemical treatments were applied immediately after Xylella fastidiosa Temecula 1 inoculations and repeated twice at monthly intervals; dpi = days postinoculation. Bars represent average \pm standard deviation for five replicates. Means ( \pm standard deviation) marked with different letters are significantly different based on Tukey-Kramer's mean separation $(P \leq 0.05)$. 
respectively, in photosynthetic gas exchange as compared with untreated and uninoculated plants.

\section{DISCUSSION}

In this study, a high-throughput screening assay for $X$. fastidiosa cell viability was developed using fluorescence and OD measurements. GFP-marked X. fastidiosa Temecula 1 was used to screen two Prestwick combinatorial small-molecule libraries (phytochemicals and drugs approved by the Food and Drug Administration and European Medicines Agency; 1,600 chemicals in total) for $X$. fastidiosa cell growth inhibition. None of the compounds from either library exhibited enhanced inhibition in the presence of Silwet L-77 at $200 \mathrm{ppm}$, indicating any effect on MDR efflux. Several of the chemicals identified as growth inhibitory or promoting cell lysis were eliminated from further consideration either for being cost prohibitive or for current pharmacological uses and therefore likely to face serious regulatory concerns. Based on primary and secondary screening data, menadione and benzethonium chloride were identified as promising lead discoveries for chemical control of PD.

Leaf disc senescence assays were used in an attempt to determine effective rate limits of the chemical treatments. Leaf disc assays that measure chlorophyll loss as a function of phytotoxicity are commonly used to assess abiotic stress conditions (Jain et al. 2012, 2018). Benzethonium chloride is a surfactant that might be expected to disrupt lipid membrane structure and cause chlorophyll degradation. Consistent with its detergent like action, benzethonium chloride caused chlorophyll degradation when applied to leaf discs in a dose-dependent manner (Fig. 3). Menadione also caused significant chlorophyll degradation in the grape leaf assays but the effect was not dose dependent. Menadione reduction by $\mathrm{NAD}(\mathrm{P}) \mathrm{H}$ cytochrome $\mathrm{P} 450$ oxidoreductase is required for sustained redox cycling and reactive oxygen species (ROS) generation (Gray et al. 2016). It seems likely that the available cellular NADPH pool was exhausted even at the lowest tested concentration of menadione $(25 \mathrm{mM})$, thus limiting redox cycling and ROS generation at higher menadione concentrations.

Both menadione and benzethonium chloride were further evaluated as potential treatments for PD by both soil drench and spray applications and for phytotoxicity to grape leaves. Based on both chlorophyll degradation assays (Fig. 3) and photosynthesis measurements (Fig. 6), menadione was strongly phytotoxic when applied directly to grapevine leaves, consistent with the observed apoptotic cell death response in menadione-treated plant cells (Sirisha et al. 2014; Sun et al. 1999). When applied as soil drenches, both chemicals significantly reduced progression of PD symptoms (54 to $59 \%$ compared with untreated controls) over a period of 3 months, demonstrating that the effects of the chemical treatments were systemic and highly efficacious.

Liposoluble compounds such as menadione influence both the integrity and fluidity of bacterial membranes (Pretto et al. 2004) and have been shown to enhance antibiotic activity via increased cell membrane permeability (Andrade et al. 2017), while also affecting bacterial efflux systems (Tintino et al. 2018). At low concentrations, menadione acts as a plant defense activator by generating ROS at multiple cellular sites (Gray et al. 2016), thus enhancing both local and systemic resistance to pathogens. Menadione pretreatments triggered redox-dependent defense gene expression in oilseed rape (Brasscia napus), resulting in effective disease resistance against stem canker caused by Leptosphaeria maculans (Borges et al. 2003). Likewise, enhanced biosynthesis and accumulation of antifungal phytoalexins was observed in menadione-pretreated banana (Musa acuminata) plants infected with Panama disease pathogen Fusarium oxysporum f. sp. cubense (Borges et al. 2004). Menadione pretreatments suppressed gray mold (Botrytis cinera) symptoms on tomato leaves through reduced conidia germination and mycelial growth (Hong et al. 2016).
Xylem parenchyma cells provide $\mathrm{H}_{2} \mathrm{O}_{2}$ that is necessary for the lignification of differentiating xylem vessels (Ros Barcelo 2005), thereby exposing the xylem-limited $X$. fastidiosa to an extremely oxidative environment at steady-state levels within the xylem sap. Therefore, in addition to being directly antimicrobial, it is highly likely that menadione induces the oxidative burden, including $\mathrm{H}_{2} \mathrm{O}_{2}$ (Gray et al. 2016), to highly antimicrobial levels. Further, $\mathrm{H}_{2} \mathrm{O}_{2}$ compromises $X$. fastidiosa OxyR, an oxidative stress regulatory protein that is essential for surface attachment, cell-to-cell aggregation, and biofilm maturation (Wang et al. 2017). Successful xylem colonization by $X$. fastidiosa is dependent upon delaying immune recognition and elicitation of a host-mediated oxidative burst (Rapicavoli et al. 2018b).

Benzethonium chloride is a synthetic quaternary ammonium salt commonly used as a topical disinfectant in the food industry and in antiseptic preparations. Benzethonium chloride exhibits broadspectrum microbicidal activity against bacteria and viruses (Sickbert-Bennett et al. 2005), human tumor cells (Yip et al. 2006), and pathogenic free-living amoebae Acanthamoeba lugdunensis and A. quina (Lukáč et al. 2013). Siles et al. (2013) identified benzethonium chloride as a lead compound in a smallmolecule screen for inhibition of Candida albicans biofilm formation.

$X$. fastidiosa causes some of the most serious plant diseases worldwide and in a wide variety of hosts, including (i) PD of grapevines in the United States (X. fastidiosa subsp. fastidiosa), (ii) citrus variegated chlorosis in sweet orange and coffee and leaf scorch in Brazil (X. fastidiosa subsp. pauca), (iii) leaf scorch of oleander ( $X$. fastidiosa subsp. sandyi), (iv) leaf scorch of mulberry and blueberry in the United States (X. fastidiosa subsp. morus), and (v) leaf scorch diseases in North America on a wide range of tree species such as almond, peach, and oak (X. fastidiosa subsp. multiplex) (Almeida and Nunney 2015; Nunney et al. 2014; Rapicavoli et al. 2018a), and more recently associated with quick decline of olive trees in Italy ( $X$. fastidiosa subsp. pauca) (Saponari et al. 2017). Both menadione and benzethonium chloride used as soil drenches caused systemic effects on $X$. fastidiosa in $V$. vinifera

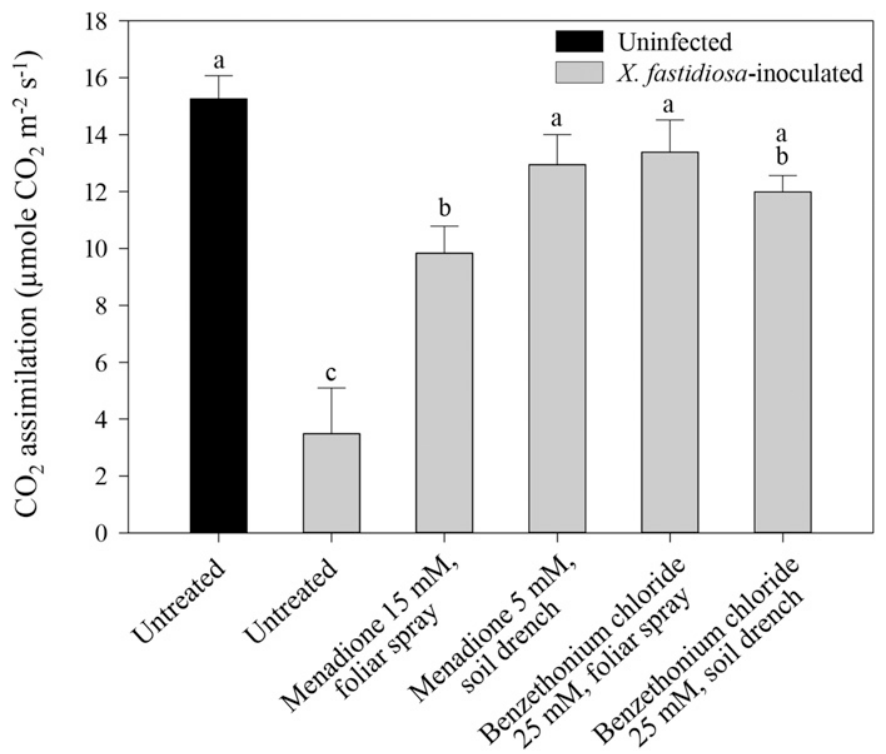

Fig. 6. Effect of menadione and benzethonium chloride applied as soil drench or foliar spray on photosynthetic $\mathrm{CO}_{2}$ assimilation rates (leaf $\mathrm{CO}_{2}$ concentration at $350 \mu \mathrm{bar}$ ) in Xylella fastidiosa Temecula 1 -inoculated Vitis vinifera 'Carignane' grapevine leaves. Chemical treatments were applied immediately after inoculations. Gas exchange data were collected from four leaves from each plant one month postinoculation. Means ( \pm standard deviation) marked with different letters are significantly different based on Tukey-Kramer's mean separation $(P \leq 0.05)$. 
grapevines, and reduced PD symptoms and disease progression by approximately $50 \%$. There is no reason to believe that either chemical would not also have systemic effects and potential applications as soil drench treatments for citrus, coffee, olive, or blueberry. Menadione is used in animal feed and pet foods as a vitamin K substitute and the cost of both chemicals is relatively low. One of the major limiting factors to growing $V$. vinifera grape in Florida is PD, and these two potential chemical control treatments should be considered for field trials to control Xylella diseases of several crops in addition to grapevines.

\section{LITERATURE CITED}

Almeida, R. P. P., and Nunney, L. 2015. How do plant diseases caused by Xylella fastidiosa emerge? Plant Dis. 99:1457-1467.

Alston, J. M., Fuller, K. B., Kaplan, J. D., and Tumber, K. P. 2015. Assessing the returns to $R \& D$ on perennial crops: The costs and benefits of Pierce's disease research in the California winegrape industry. Aust. J. Agric. Resour. Econ. 59:95-115.

Andrade, J. C., Braga, M. F. B. M., Guedes, G. M. M., Tintino, S. R., Freitas, M. A., Quintans, L. J., Jr., Menezes, I. R., and Coutinho, H. D. 2017. Menadione (vitamin K) enhances the antibiotic activity of drugs by cell membrane permeabilization mechanism. Saudi J. Biol. Sci. 24:59-64.

Arnon, D. I. 1949. Copper enzymes in isolated chloroplasts. Polyphenoloxidase in Beta vulgaris. Plant Physiol. 24:1-15.

Barabote, R. D., Johnson, O. L., Zetina, E., San Francisco, S. K., Fralick, J. A., and San Franscisco, M. J. D. 2003. Erwinia chrysanthemii tolC is involved in resistance to antimicrobial plant chemicals and is essential in phytopathogenesis. J. Bacteriol. 185:5772-5778.

Borges, A. A., Borges-Pérez, A., and Fernández-Falcón, M. 2004. Induced resistance to Fusarial wilt of banana by menadione sodium bisulphite treatments. Crop Prot. 23:1245-1247.

Borges, A. A., Cools, H. J., and Lucas, J. A. 2003. Menadione sodium bisulphite: A novel plant defence activator which enhances local and systemic resistance to infection by Leptosphaeria maculans in oilseed rape. Plant Pathol. 52:429-436.

Burse, A., Weingart, H., and Ullirch, M. S. 2004. The phytoalexin-inducible multidrug efflux pump $A$ crAB contributes to virulence in the fire blight pathogen, Erwinia amylovora. Mol. Plant-Microbe Interact. 17: 443-454.

Chatterjee, S., Almeida, R. P. P., and Lindow, S. 2008. Living in two worlds: The plant and insect lifestyles of Xylella fastidiosa. Annu. Rev. Phytopathol. 46:243-271.

Delepelaire, P. 2004. Type I secretion in Gram-negative bacteria. Biochim. Biophys. Acta 1694:149-161.

Gonzales-Pasayo, R., and Martinez-Romera, E. 2000. Multiresistance genes of Rhizobium etli CFN42. Mol. Plant-Microbe Interact. 13:572-577.

Goodwin, P. H., DeVay, J. E., and Meredith, C. P. 1988. Roles of water stress and phytotoxins in the development of Pierce's disease of the grapevine. Physiol. Mol. Plant Pathol. 32:1-15.

Gray, J. P., Karandrea, S., Burgos, D. Z., Jaiswal, A. A., and Heart, E. A. 2016. $\mathrm{NAD}(\mathrm{P}) \mathrm{H}$-dependent quinone oxidoreductase 1 (NQO1) and cytochrome P450 oxidoreductase (CYP450OR) differentially regulate menadionemediated alterations in redox status, survival and metabolism in pancreatic $\beta$-cells. Toxicol. Lett. 262:1-11.

Guilhabert, M. R., and Kirkpatrick, B. C. 2005. Identification of Xylella fastidiosa antivirulence genes: Hemagglutinin adhesins contribute to $X$. fastidiosa biofilm maturation and colonization and attenuate virulence. Mol. Plant-Microbe Interact. 18:856-868.

Holland, I. B., Schmitt, L., and Young, J. 2005. Type 1 protein secretion in bacteria, the ABC-transporter dependent pathway. Mol. Membr. Biol. 22: 29-39.

Hong, J. K., Kim, H. J., Jung, H., Yang, H. J., Kim, D. H., Sung, C. H., Park, C. J., and Chang, S. W. 2016. Differential control efficacies of vitamin treatments against bacterial wilt and grey mold diseases in tomato plants. Plant Pathol. J. 32:469-480.

Jain, M., Munoz-Bodnar, A., Zhang, S., and Gabriel, D. W. 2018. A secreted 'Candidatus Liberibacter asiaticus' peroxiredoxin simultaneously suppresses both localized and systemic innate immune responses in planta. Mol. Plant-Microbe Interact. 31:1312-1322.

Jain, S., Kumar, D., Jain, M., Chaudhary, P., Deswal, R., and Sarin, N. B. 2012. Ectopic overexpression of a salt stress-induced pathogenesis-related class 10protein (PR10) gene from peanut (Arachis hypogaea L.) affords broad spectrum abiotic stress tolerance in transgenic tobacco. Plant Cell Tissue Organ Cult. 109:19-31.

Kovach, M. E., Elzer, P. H., Hill, D. S., Robertson, G. T., Farris, M. A., and Roop, R. M. 1995. Four new derivatives of the broad host-range cloning vector pBBR1MCS, carrying different antibiotic-resistance cassettes. Gene 166:175-176.

Krummenacher, P., and Narberhaus, F. 2000. Two genes encoding a putative multidrug efflux pump RND/MFP family are cotranscribed with an $r p o H$ gene in Bradyrhizobium japonicum. Gene 241:247-254.

Lukáč, M., Mrva, M., Garajová, M., Mojžǐ̌ová, G., Varinská, L., Mojžiš, J., Sabol, M., Kubincová, J., Haragová, H., Ondriska, F., and Devínsky, F. 2013. Synthesis, self-aggregation and biological properties of alkylphosphocholine and alkylphosphohomocholine derivatives of cetyltrimethylammonium bromide, cetylpyridinium bromide, benzalkonium bromide (C16) and benzethonium chloride. Eur. J. Med. Chem. 66:46-55.

Murashige, T., and Skoog, F. 1962. A revised medium for rapid growth and bio assays with tobacco tissue cultures. Physiol. Plant. 15:473-497.

Nunney, L., Ortiz, B., Russell, S. A., Sánchez, R. R., and Stouthamer, R. 2014. The complex biogeography of the plant pathogen Xylella fastidiosa: Genetic evidence of introductions and subspecific introgression in Central America. PLoS One 9:e112463.

Peng, W. T., and Nester, E. W. 2001. Characterization of a putative RND type efflux system in Agrobacterium tumefaciens. Gene 270:245-252.

Pretto, J. B., Cechinel Filho, V., Noldin, V. F., Sartori, M. R. K., Isaias, D. E. B., and Bella, C. A. Z. 2004. Antimicrobial activity of fractions and compounds from Calophyllum brasiliense (Clusiaceae/Guttiferae). Naturforsch. 59:657-662.

Purcell, A. H., and Hopkins, D. L. 1996. Fastidious xylem-limited bacterial plant pathogens. Annu. Rev. Phytopathol. 34:131-151.

Rapicavoli, J., Ingel, B., Blanco-Ulate, B., Cantu, D., and Roper, C. 2018a. Xylella fastidiosa: An examination of a re-emerging plant pathogen. Mol. Plant Pathol. 19:786-800.

Rapicavoli, J. N., Blanco-Ulate, B., Muszyński, A., Figueroa-Balderas, R., Morales-Cruz, A., Azadi, P., Dobruchowska, J. M., Castro, C., Cantu, D., and Roper, M. C. 2018b. Lipopolysaccharide O-antigen delays plant innate immune recognition of Xylella fastidiosa. Nat. Commun. 9:390.

Reddy, J. D., Reddy, S. L., Hopkins, D. L., and Gabriel, D. W. 2007. TolC is required for pathogenicity of Xylella fastidiosa in Vitis vinifera grapevines. Mol. Plant-Microbe Interact. 20:403-410.

Ros Barcelo, A. 2005. Xylem parenchyma cells deliver the $\mathrm{H}_{2} \mathrm{O}_{2}$ necessary for lignification in differentiating xylem vessels. Planta 220:747-756.

Saponari, M., Boscia, D., Altamura, G., Loconsole, G., Zicca, S., D'Attoma, G., Morelli, M., Palmisano, F., Saponari, A., Tavano, D., and Savino, V. N. 2017. Isolation and pathogenicity of Xylella fastidiosa associated to the olive quick decline syndrome in southern Italy. Sci. Rep. 7: Article 17723.

Sickbert-Bennett, E. E., Weber, D. J., Gergen-Teague, M. F., Sobsey, M. D., Samsa, G. P., and Rutala, W. A. 2005. Comparative efficacy of hand hygiene agents in the reduction of bacteria and viruses. Am. J. Infect. Control 33:67-77.

Siles, S. A., Srinivasan, A., Pierce, C. G., Lopez-Ribot, J. L., and Ramasubramanian, A. K. 2013. High-throughput screening of a collection of known pharmacologically active small compounds for the identification of Candida albicans biofilm inhibitors. Antimicrob. Agents Chemother. 57: 3681-3687. link

Sirisha, V. L., Sinha, M., and D'Souza, J. S. 2014. Menadione-induced caspase-dependent programmed cell death in the green chlorophyte Chlamydomonas reinhardtii. J. Phycol. 50:587-601.

Steff, A. M., Fortin, M., Arguin, C., and Hugo, P. 2001. Detection of a decrease in green fluorescent protein fluorescence for the monitoring of cell death: An assay amenable to high throughput screening technologies. Cytometry 45:237-243.

Stevenson, J., Matthews, M., and Rost, T. 2005. The developmental anatomy of Pierce's disease symptoms in grapevines: Green islands and matchsticks. Plant Dis. 89:543-548.

Sun, Y.-L., Zhao, Y., Hong, X., and Zhai, Z.-H. 1999. Cytochrome c release and caspase activation during menadione-induced apoptosis in plants. FEBS Lett. 462:317-321.

Tegos, G., Stermitz, F. R., Lomovskaya, O., and Lewis, K. 2002. Multidrug pump inhibitors uncover remarkable activity of plant antimicrobials. Antimicrob. Agents Chemother. 46:3133-3141.

Tegos, G. P., Haynes, M., Strouse, J. J., Khan, M. M., Bologa, C. G., Oprea, T. I., and Sklar, L. A. 2011. Microbial efflux pump inhibition: Tactics and strategies. Curr. Pharm. Des. 17:1291-1302.

Thorne, E. T., Stevenson, J. F., Rost, T. L., Labavitch, J. M., and Matthews, M. A. 2006. Pierce's disease symptoms: Comparison with symptoms of water deficit and the impact of water deficits. Am. J. Enol. Vitic. 57: $1-11$.

Tintino, S. R., Oliveira-Tintino, C. D., Campina, F. F., Limaverde, P. W., Pereira, P. S., Siqueira-Junior, J. P., Coutinho, H. D., Quintans-Júnior, L. J., da Silva, T. G., Leal-Balbino, T. C., and Balbino, V. Q. 2018. Vitamin K enhances the effect of antibiotics inhibiting the efflux pumps of Staphylococcus aureus strains. Med. Chem. Res. 27:261-267. 
Wang, P., Lee, Y., Igo, M. M., and Roper, M. C. 2017. Tolerance to oxidative stress is required for maximal xylem colonization by the xylemlimited bacterial phytopathogen, Xylella fastidiosa. Mol. Plant Pathol. 18:990-1000.

Yip, K. W., Mao, X., Au, P. B., Hedley, D. W., Chow, S., Dalili, S., Mocanu, J. D., Bastianutto, C., Schimmer, A., and Liu, F. F. 2006. Benzethonium chloride: A novel anticancer agent identified by using a cell-based small-molecule screen. Clin. Cancer Res. 12:55575569 .
Zhang, J. H., Chung, T. D., and Oldenburg, K. R. 1999. A simple statistical parameter for use in evaluation and validation of high throughput screening assays. J. Biomol. Screen. 4:67-73.

Zhang, S., Chakrabarty, P. K., Fleites, L. A., Rayside, P. A., Hopkins, D. L., and Gabriel, D. W. 2015. Three new Pierce's disease pathogenicity effectors identified using Xylella fastidiosa biocontrol strain EB92-1. PLoS One 10:e133796. Zhang, Y., Callaway, E. M., Jones, J. B., and Wilson, M. 2009. Visualisation of hrp gene expression in Xanthomonas euvesicatoria in the tomato phyllosphere. Eur. J. Plant Pathol. 124:379-390. 